\title{
Caracterización de la Competencia Informacional y su aporte al aprendizaje de usuarios de información: una experiencia en la formación profesional en psicología *
}

\author{
Jorge Winston Barbosa Chacón ** \\ Gloria Patricia Marciales Vivas ***

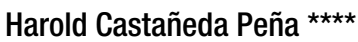

Artículo recibido:

17 de septiembre de 2014.

Artículo aceptado:

9 de octubre de 2014.

\section{Resumen}

Se presentan los resultados de una investigación cuyo objetivo principal es el apoyo al aprendizaje de usuarios de información en educación profesional universitaria. La estrategia metodológica, que tiene como contexto un programa profesional de psicología en una

* Este artículo presenta los resultados de la investigación del grupo Aprendizaje y Sociedad de la Información, integrado por profesores de la Pontificia Universidad Javeriana (PUJ), la Universidad Industrial de Santander (UIS) y la Universidad Distrital Francisco José de Caldas. Proyectos vinculados: PRE00439014390, PS4663-Vicerrectoría Académica PUJ; CH20092, CH 2012-2-Vicerrectoría de Investigación y Extensión UIS. Se reconoces los aportes de los profesores Luis Bernardo Peña y Gustavo La Rotta Amaya, agentes vinculados al desarrollo del Proyecto de Indagación (PRIN) de la PUJ.

** Universidad Industrial de Santander-Bucaramanga, Colombia. jowins@uis.edu.co

*** Pontificia Universidad Javeriana-Bogotá, Colombia. gloria.marciales@javeriana. edu.co

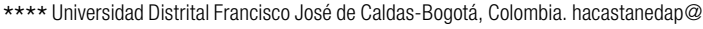
distrital.uis.edu.co 
universidad colombiana, se estructuró y desarrolló en tres fases consecutivas: i) reconceptualización, observación y caracterización de competencias informacionales desde la perspectiva semiótica del discurso; ii) confrontación con retos, necesidades y problemas que plantea la investigación a la educación profesional universitaria y iii) propuesta de apoyo a la formación de estudiantes de primer semestre desde el marco del desarrollo de competencias investigativas, informacionales y lecto-escriturales. Se concluye denotando la importancia y los logros obtenidos cuando se armonizan los diferentes roles y procesos que apoyan el aprendizaje de los usuarios de información, en particular cuando se tienen en cuenta las dimensiones contextuales, disciplinares y educativas y, en especial, la sinergia ante el desarrollo de competencias de diferente orden.

Palabras clave: Educación Superior; Investigación en Ciencias Sociales; Alfabetización Informacional; Desarrollo de Competencias; Semiótica.

\section{Abstract \\ Information literacy typification and its contribution to learning of information users: A higher education experience \\ Jorge Winston Barbosa-Chacón, Gloria Patricia Marcia- les Vivas and Harold Castañeda-Peña}

This paper presents results of research aimed at supporting information user learning in an undergraduate psychology program of a Colombian university, where the following methodological steps were followed: 1) From the perspective of a semiotic framework, information-literacy competencies were reconceived, and after a period of observation, re-typified. 2) Research on information-literacy competencies was contrasted with challenges, needs and problems in the context of undergraduate education. 3) A proposal is forwarded that addresses information literacy, research and academic-writing competencies needed by first-year undergrads. Results show the importance of coordinating roles and processes that are mindful of specific educational contexts and disciplines. These factors are especially significant in promoting information user 
learning and the wealth of synergies that arise from the attainment of competencies of diverse orders.

Keywords: Higher Education; Social Science Research; Information Literacy; Competencies Development; Semiotics.

\section{INTRODUCCIÓN}

Caracterizar la competencia informacional (CI) es una gestión compleja por la naturaleza polisémica del concepto, la multiplicidad de variables vinculadas y el escaso respaldo conceptual existente desde perspectivas menos instrumentales. Adicionalmente, los desarrollos epistemológicos y teóricos en torno a las formas de entender a los usuarios de información se encuentran arraigados en los contextos históricos y culturales que rodean la relación persona-información y, por ende, expresan diversas formas de entender lo que significa ser competente informacionalmente (Marciales Vivas et al., 2010).

Esta complejidad explica, en parte, los escasos medios para dar cuenta de la naturaleza de las CI. De allí que la caracterización de los usuarios de información, a partir de la articulación de variables asociadas a la competencia en un todo comprensivo y coherente, sea un aporte importante para este campo de problemas (Marciales Vivas et al., 2010).

Una manera de comprometerse con el anterior reto es a través de la articulación de los resultados de investigación sobre CI con los procesos de formación universitaria, articulación que representa el horizonte de este artículo al presentar una experiencia de investigación e intervención realizada en la Pontificia Universidad Javeriana (PUJ), ${ }^{1}$ específicamente en el programa de Psicología.

La experiencia fue adelantada por el grupo de investigación Aprendizaje y Sociedad de la Información, ${ }^{2}$ que realizó un estudio de caracterización de la CI en estudiantes de primer semestre. Este estudio brindó elementos para una propuesta de formación que, adicionalmente, favorece el desarrollo de competencias en investigación y lecto-escritura; una propuesta que, dado su

1 Ver información de la PUJ en: http://puj-portal.javeriana.edu.co/portal/page/portal/PORTAL_ VERSION_2009_2010/es_inicio

2 Ver integrantes y experiencia investigativa del grupo en el siguiente enlace: http://201. 234.78.173:8080/gruplac/jsp/visualiza/visualizagr.jsp?nro=00000000001836 
alcance, es responsabilidad compartida entre profesionales de las ciencias de la información, profesores e investigadores del programa.

En correspondencia, en este artículo se documentan las diferentes fases de la experiencia investigativa a través de seis secciones que dan respuesta a interrogantes específicos: ¿cuál es el contexto de intervención y el diseño investigativo? ¿Cuál fue la experiencia de reconceptualización? ¿Cuál fue la experiencia de caracterización? ¿Qué retos plantea la investigación a la formación de usuarios de información universitarios? ¿Cómo apoyar el aprendizaje de usuarios de información en la universidad? ¿Cuál es la reflexión y discusión final?

\section{¿CUÁL ES EL CONTEXTO DE INTERVENCIÓN Y EL DISEÑO INVESTIGATIVO? EL PROGRAMA ACADÉMICO Y LA APUESTA DE INVESTIGACIÓN}

Psicología es un programa presencial de pregrado ${ }^{3}$ adscrito a la facultad del mismo nombre en la PUJ. Desde su currículo se propende por la formación de personas interesadas en aspectos como: i) Comprensión sobre los campos de actuación de la psicología; ii) Comprensión y compromiso con las problemáticas sociales del país; iii) Competencias sociales para establecer relaciones y trabajar en equipo; iv) Responsabilidad en sus acciones y compromisos académicos y v) Capacidad de autoreflexión y flexibilidad para enfrentar las situaciones de su vida personal.

El plan de estudios de Psicología está estructurado con base en dos elementos conceptuales: los campos de formación y los ejes problemáticos con sus respectivas dimensiones transversales. En cuanto a campos de formación, la propuesta formativa los contempla como una perspectiva para referir y entender la disciplina y la profesión como un espacio estructurado de conocimiento y de desarrollo disciplinar. Al respecto, en el Cuadro 1 se describen los cuatro campos de formación del programa.

3 Ampliar detalles del programa en: http://puj-portal.javeriana.edu.co/portal/page/portal/Facultad\%20de\%20Psicologia/INICIO 
Cuadro 1. Campos de formación del programa de Psicología de la PUJ

\begin{tabular}{|c|c|c|}
\hline & & Descripción \\
\hline \multirow{4}{*}{ 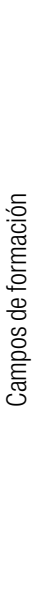 } & $\begin{array}{l}\text { Fundamentación } \\
\text { psicológica }\end{array}$ & $\begin{array}{l}\text { Las reflexiones y los conocimientos que han permitido el desarrollo de la psi- } \\
\text { cología como disciplina y profesión constituyen el objeto de trabajo; incluye las } \\
\text { preguntas por la constitución del objeto de estudio, la formulación de teorías del } \\
\text { desarrollo y su estatuto en el campo científico, así como la relación entre sujeto y } \\
\text { grupo social. }\end{array}$ \\
\hline & $\begin{array}{l}\text { Conocimientos } \\
\text { específicos }\end{array}$ & $\begin{array}{l}\text { Alude a los campos sociales, de acción e investigación, en los cuales la psicolo- } \\
\text { gía ha desarrollado un saber pertinente. Busca tematizar las relaciones entre el } \\
\text { conocimiento y los problemas sociales. A los cuatro campos tradicionales de la } \\
\text { psicología (clínico, educativo, organizacional y social) se incorporan dos más: la } \\
\text { psicología jurídica y la neuropsicología, poniendo de relieve la continua influencia } \\
\text { de la psicología en el mundo social y cultural. }\end{array}$ \\
\hline & $\begin{array}{l}\text { Formación } \\
\text { metodológica e } \\
\text { investigativa }\end{array}$ & $\begin{array}{l}\text { Plantea los fundamentos epistemológicos, teóricos, conceptuales, lógicos y técni- } \\
\text { co-instrumentales para desarrollar en el estudiante la comprensión e implemen- } \\
\text { tación de métodos y procedimientos pertinentes para la investigación y la inter- } \\
\text { vención en psicología. }\end{array}$ \\
\hline & $\begin{array}{l}\text { Formación } \\
\text { multidisciplinar }\end{array}$ & $\begin{array}{l}\text { Esta línea articula en un conjunto amplio la dimensión teológica y ética, las opcio- } \\
\text { nes complementarias y las asignaturas electivas de la carrera. }\end{array}$ \\
\hline
\end{tabular}

Fuente: basado en la información del sitio web del programa ${ }^{4}$

Con respecto a los ejes problemáticos, los agentes educativos los entienden como líneas articuladoras de problemas pertinentes para la psicología, alrededor de las cuales se agrupan preguntas que se nutren de los avances de la disciplina, los debates académicos, la producción de los grupos de investigación y las orientaciones normativas de la formación de psicólogos en pregrado; así, las líneas articuladoras se despliegan en cuatro dimensiones, a saber: histórica, epistemológica, metodológica y teórica.

Como se puede apreciar con base en las características del egresado y en los elementos conceptuales de la propuesta educativa, ésta es digna de ser fortalecida en concordancia con las exigencias y tendencias del campo de formación específico, reto que exige ser visto y afrontado desde la perspectiva de investigación e intervención, en donde se integren los diferentes agentes educativos participantes en el desarrollo del programa. Se intuye entonces que los elementos conceptuales del programa y los componentes de formación demandan retos educativos que trascienden lo disciplinar, siendo un ejemplo de ello el desarrollo de las competencias informacionales. Este compromiso exige la caracterización de las mismas en los estudiantes y, más aún, la visualización de propuestas de formación que se articulen con el favorecimiento de otras competencias también de naturaleza transversal.

4 Ver: http://puj-portal.javeriana.edu.co/portal/page/portal/Facultad\%20de\%20Psicologia/plt_ psicologia/Plan\%20estudios 
En correspondencia con la anterior exigencia, los miembros del grupo de investigación, como agentes influyentes en el programa, trazaron una apuesta investigativa que tuvo como objetivo contribuir a dar respuestas a interrogantes relacionados con la caracterización de los estudiantes como usuarios de información, para así apoyar la formulación y ejecución de propuestas formativas en correspondencia. Para ello, y en cuanto a metodología se refiere, se formuló una apuesta investigativa que se estructuró en cuatro fases o experiencias particulares:

- Fase I-Marco de referencia. Representa la experiencia encaminada a la determinación de los referentes conceptuales y teóricos que respaldan el estudio de caracterización de la CI.

- Fase II-Caracterización. Experiencia de construcción de un instrumento para la observación de la CI y su respectivo proceso de caracterización. Esta fase contó con dos diseños investigativos específicos, los cuales son pormenorizados más adelante.

- Fase III-Complementación. Experiencia de determinación de retos, necesidades y problemas relevantes, emanados de investigaciones asociadas al objeto y contexto de estudio.

- Fase IV-Propuesta de intervención. Experiencia de aplicación de resultados de la apuesta investigativa.

\section{¿CUÁL FUe LA EXPERIENCIA DE RECONCEPTUALIZACIÓN? El PUNTO DE} PARTIDA PARA CARACTERIZAR LAS COMPETENCIAS INFORMACIONALES

Las publicaciones que respaldan los aportes teóricos e investigativos sobre CI destacan la concepción tradicional de la Association of College and Research Library (ACRL, 2000) y de la American Library Association (ALA, 1989), perspectiva desde la cual ser competente informacionalmente significa ser capaz de reconocer cuándo se necesita información y tener la habilidad para localizarla, entender su organización, evaluarla, usarla efectivamente y aprender a partir de las relaciones con la misma (Marciales Vivas et al., 2010; Barbosa-Chacón et al., 2010).

Tales trabajos destacan dos aspectos: por un lado, el énfasis relacionado con la adquisición, el desarrollo y la demostración de habilidades individuales; por otro, la identificación de prácticas de búsqueda, evaluación y uso de la información (Marciales Vivas et al., 2010). Estos aspectos son objeto de discrepancia y explican la distancia entre las definiciones tradicionales de la 
competencia y la reconceptualización que aquí se propone, la cual subyace a la caracterización de perfiles de CI.

La propuesta de reconceptualización inicia dando importancia a la historia del concepto en la ciencia de la información, el cual ha trasegado por tres momentos: i) el de predominio de una perspectiva objetivista en la cual su evaluación se centró en la medición de conocimiento a través de pruebas objetivas; ii) en el que se da importancia al procesamiento de información y iii) en el que se incorpora al concepto el entorno cultural y social de los usuarios; desplazamiento que obedece a la influencia del pensamiento de Vygotsky a mediados de los noventa (Montiel-Overall, 2007).

La reconceptualización propuesta aquí, ubicada en el tercer momento, se enmarca en una perspectiva cuyos aspectos se muestran en el Cuadro 2.

Cuadro 2. Perspectiva sociocultural de la competencia informacional

\begin{tabular}{|c|c|c|}
\hline \multicolumn{3}{|c|}{ Aspectos relevantes de la perspectiva sociocultural de la $\mathrm{Cl}$} \\
\hline$\frac{\mathscr{d}}{\frac{\mathscr{O}}{\overparen{\frac{O}{E}}}}$ & \multicolumn{2}{|c|}{$\begin{array}{l}\text { - La cultura, inseparable de la forma como los sujetos piensan y aprenden. } \\
\text { - La actividad humana situada en un contexto de interacción social y cultural. } \\
\text { - La interacción con otros como mediadora de la construcción de conocimiento. } \\
\text { - Las diferencias culturales y contextuales como base de configuración de ideas y prácticas cotidia- } \\
\text { nas. }\end{array}$} \\
\hline$\frac{\mathscr{\mathscr { C }}}{\stackrel{\bar{\omega}}{\bar{a}}}$ & \multicolumn{2}{|c|}{$\begin{array}{l}\text { - La incidencia de factores socioculturales en la evolución de las competencias. } \\
\text { - La mediación de la cultura en la forma como el sujeto construye significados a partir de la informa- } \\
\text { ción y en su forma de actuar. } \\
\text { - La flexibilidad o dinamismo de la Cl. }\end{array}$} \\
\hline \multirow{3}{*}{ 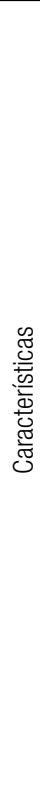 } & \multicolumn{2}{|c|}{$\begin{array}{l}\text { - Se reconoce la autoridad de los individuos y las comunidades al crear, evaluar y usar información, } \\
\text { no solamente la autoridad de las fuentes validadas por comunidades científicas. } \\
\text { - Se entiende que toda información tiene sesgos, por lo tanto, hacerse competente informacional } \\
\text { mente supone desarrollar la capacidad para identificarlos. } \\
\text { - La información no existe como una realidad objetiva, sino que es construida por los individuos den } \\
\text { tro de un contexto sociocultural y continuamente transforma y es transformada por la realidad. E } \\
\text { un instrumento para crear conocimiento influido por factores culturales relacionados por la forma } \\
\text { en que la información es creada en las comunidades, la manera cómo se transmite y el contexto er } \\
\text { donde se usa. }\end{array}$} \\
\hline & $\begin{array}{l}\text { Cl como práctica con dimensión } \\
\text { social y cultural. }\end{array}$ & $\begin{array}{l}\text { Supone la existencia de un nexo entre su desarrollo y la formación } \\
\text { de un sujeto social, capaz de asumir, con crítica y ética, la diversi- } \\
\text { dad de factores culturales que median el acceso a la información. }\end{array}$ \\
\hline & Dimensión histórica de la Cl & $\begin{array}{l}\text { - El usuario de la información es un sujeto dinámico y cambiante. } \\
\text { - La historia del sujeto se constituye en fuente de recuerdo y de ol- } \\
\text { vido, y establece continuidades y discontinuidades, para el caso, } \\
\text { asociadas a la forma de acceder, evaluar, hacer uso y apropiarse } \\
\text { de la información. } \\
\text { - Son relevantes los instrumentos y prácticas nacientes de las in- } \\
\text { teracciones en las comunidades de referencia de los usuarios de } \\
\text { la información, las cuales inciden en las creencias y prácticas. } \\
\text { - Las interacciones se configuran como instrumento de construc- } \\
\text { ción de significados y se expresan en las formas habituales de } \\
\text { relacionarse con la información en contextos específicos. }\end{array}$ \\
\hline
\end{tabular}


- La apropiación de información, en contextos culturales específicos, representa un papel fundamental para el desarrollo de competencias y de capital social.

Fuente: Adaptado de Marciales Vivas et al. (2010: 646-648) y Barbosa-Chacón et al. (2010, 2012: 128-131)

A partir de los planteamientos anteriores se propone una definición de las CI que sustenta un "giro" en la definición tradicional:

Competencia informacional es el entramado de relaciones tejidas entre las adhesiones y creencias, las motivaciones y las aptitudes del sujeto epistémico, construidas a lo largo de su historia en contextos situados de aprendizaje, formales y no formales. Tal entramado de relaciones actúa como matriz de referencia de las formas de apropiación de la información, que tienen lugar a través del acceder, evaluar, y hacer uso de ésta, y que expresan los contextos culturales en los cuales fueron construidas. (Barbosa-Chacón et al., 2010: 137.)

Así definida, la CI se asume como un constructo en el que se relacionan las condiciones y presupuestos que articulan cuatro modalidades: Potencializante, Virtualizante, Actualizante y Realizante (Greimas, 1989; Serrano Orejuela, 2003: Alvarado, 2007; Rosales, 2008). Para Greimas: i) La competencia se configura como el ser del hacer, un estado potencial en donde el acto es una estructura hipotáctica que reúne la competencia y la ejecución y ii) El saber hacer corresponde tan sólo a una de las modalidades que constituye la competencia, entendida ésta como el ser del hacer que antecede a la ejecución. Por lo anterior, la competencia está constituida por las condiciones previas que hacen posible la acción. La ejecución en sí misma no es otra cosa que la forma realizada de la acción, mas no la competencia propiamente dicha (Alvarado, 2007).

Dados los aportes, el sujeto que usa fuentes de información se constituye como tal en tanto que actúa mediado por diferentes condiciones: saber hacer (competencia cognitiva); poder hacer (capacidad); querer hacer (voluntad); deber hacer (prescripción). Finalmente, cuando es modalizado por sus creencias, significa que ha asumido los determinantes tanto de su cultura como de su grupo social (Alvarado, 2007).

Los niveles o modos de existencia se exponen en el Cuadro 3, en el cual se incluyen datos provenientes de estudios de caso ${ }^{5}$ (ver criterios de desarrollo en el Cuadro 4). Estos niveles o modos de existencia se constituyen en 
los elementos que integran y articulan la reconceptualización de la CI y, a su vez, enmarcan la caracterización de los perfiles de usuarios de la información. Una ampliación de los aspectos teóricos y procedimentales que sustentaron la reconceptualización realizada se encuentra en Marciales Vivas et al. (2008) y Barbosa-Chacón et al. (2010, 2011).

Cuadro 3. Modos de existencia de la competencia

\begin{tabular}{|c|c|c|c|}
\hline \multicolumn{3}{|c|}{ Competencia } & Ejecución \\
\hline \multicolumn{4}{|c|}{ Modos de existencia } \\
\hline Modo potencializado & Modo virtualizado & Modo actualizado & Modo realizado \\
\hline Creencias & Motivaciones & Aptitudes & Efectuaciones \\
\hline \multirow{2}{*}{$\begin{array}{c}\text { Creer, Adherir } \\
\text { (Determinaciones } \\
\text { culturales asumidas o } \\
\text { impuestas) }\end{array}$} & $\begin{array}{c}\text { Querer } \\
\text { (Voluntad) }\end{array}$ & $\begin{array}{c}\text { Saber } \\
\text { (Conocimientos) }\end{array}$ & \multirow[t]{2}{*}{ Ser-Hacer } \\
\hline & $\begin{array}{c}\text { Deber } \\
\text { (Prescripciones) } \\
\end{array}$ & $\begin{array}{c}\text { Poder } \\
\text { (Capacidad) }\end{array}$ & \\
\hline $\begin{array}{l}\text { Son las visiones del } \\
\text { mundo que se poseen, } \\
\text { las cuales se manifiestan } \\
\text { al defender una posición } \\
\text { frente a un problema, una } \\
\text { necesidad o un tema que } \\
\text { las reta. }\end{array}$ & $\begin{array}{l}\text { Comprende los deseos } \\
\text { y deberes; aquello que } \\
\text { mueve a realizar la } \\
\text { acción. }\end{array}$ & \begin{tabular}{|l|} 
Corresponde al conoci- \\
miento que se tiene sobre \\
qué hacer y cómo realizar \\
una acción. Para el caso \\
estudiantil, supone co- \\
nocimiento del contexto \\
de la "tarea o trabajo" y \\
reconocimiento de los \\
factores involucrados en \\
su solución. \\
\end{tabular} & $\begin{array}{l}\text { Es la ejecución emplean- } \\
\text { do las fuentes de infor- } \\
\text { mación. Se expresa en } \\
\text { la forma de apropiarse y } \\
\text { comunicar la elaboración } \\
\text { realizada. }\end{array}$ \\
\hline \multicolumn{4}{|c|}{ Ejemplificación (deducida de estudios de caso) } \\
\hline $\begin{array}{l}\text {. "El Internet me ofrece } \\
\text { esa ventaja de obtener } \\
\text { la información rápida". } \\
\text {. "[...] me han inculcado } \\
\text { que tengo que basarme } \\
\text { en entidades serias, } \\
\text { respetables, y no en } \\
\text { cualquier comentario } \\
\text { [...]". (EMS) }\end{array}$ & $\begin{array}{l}\text { • "[...] como lo relacio- } \\
\text { nado con las guerras } \\
\text { mundiales, son cosas } \\
\text { que siempre me han } \\
\text { llamado la atención } \\
\text { [...]". } \\
\text {. "Primero, que la } \\
\text { información es muy } \\
\text { amplia, entonces } \\
\text { tengo que verificar } \\
\text { que verdaderamente } \\
\text { la información que me } \\
\text { llegue sea correcta y } \\
\text { confiable, por decirlo } \\
\text { así". (EMS) }\end{array}$ & $\begin{array}{l}\text { - "Es simplemente darle } \\
\text { a un buscador y bajar } \\
\text { un archivo y leer la } \\
\text { información que ahí } \\
\text { está recopilada". } \\
\text {. "Entré a Google y le fui } \\
\text { dando datos precisos, } \\
\text { nombre fechas, videos } \\
\text { y otras palabras [...]". } \\
\text { (EMS) }\end{array}$ & \\
\hline
\end{tabular}

Fuente: basado en Alvarado (2007: 5-9) y adaptado de Barbosa-Chacón et al. (2010: 132-136)

6 (EMS) representa la identidad anónima del estudiante participante en el estudio de caso. 


\section{¿CuÁl FUe la EXPERIENCIA DE CARACTERIZACIÓN? LA BASE PARA LA DEDUCCIÓN DE PERFILES DE COMPETENCIA INFORMACIONAL}

\section{Con el resultado de la reconceptualización de la CI se asumió la construcción de un instrumento para su observación previa a su caracterización, compro- misos que exigieron diseños investigativos particulares, los cuales se descri- ben en el Cuadro 4. Una ampliación de los aspectos teóricos y procedimenta- les que sustentaron estos estudios puede observarse en Castañeda-Peña et al. (2010), Barbosa-Chacón et al. (2012) y González Niño et al. (2013).}

Cuadro 4. Diseños investigativos del estudio de caracterización de la competencia informacional

\begin{tabular}{|c|c|c|}
\hline & & Instrumento de observación de la $\mathrm{Cl}$ \\
\hline Preg & ta de investigación & $\begin{array}{l}\text { ¿Qué tipo de instrumento observacional se requiere para describir las } \mathrm{Cl} \text { en estu- } \\
\text { diantes universitarios? }\end{array}$ \\
\hline Obje & o general & $\begin{array}{l}\text { Construir una estrategia de observación que permitiera describir las } \mathrm{Cl} \text { de estu- } \\
\text { diantes universitarios. }\end{array}$ \\
\hline Tesis & le trabajo & $\begin{array}{l}\text { La apropiación de significados culturales que, siendo parte de la relación y em- } \\
\text { poderamiento social del sujeto, inciden en su Cl. }\end{array}$ \\
\hline & & Estudios de caso \\
\hline $\begin{array}{l}\frac{00}{0} \\
\frac{0}{0} \\
\frac{0}{0} \\
\frac{0}{0} \\
\sum\end{array}$ & $\begin{array}{l}\text { i) Determinar una t } \\
\text { del estudiante (con } \\
\text { meno a observar); } \\
\text { el cómo y el porque } \\
\text { del discurso; vi) Re } \\
\text { del estudio de caso }\end{array}$ & $\begin{array}{l}\text { area que conllevara a la consulta de fuentes de información; ii) Recoger el discurso } \\
\text { ducta individual), producto de su interacción con las fuentes de información (fenó- } \\
\text { iii) Abordar el fenómeno dentro del contexto educativo real; iv) Determinar el qué, } \\
\text { é del fenómeno; v) Visualizar evidencias que apoyan o no la perspectiva semiótica } \\
\text { ealizar registros de observación del fenómeno y vii) Diseñar y aplicar un protocolo } \\
\text {. }\end{array}$ \\
\hline 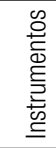 & $\begin{array}{l}\text { Fichas de observac } \\
\text { boración de un esc } \\
\text { información; ii) Du } \\
\text { información; iii) De }\end{array}$ & $\begin{array}{l}\text { ción. i) Antes: incluye un instrumento sobre aspectos sociodemográficos y la ela- } \\
\text { rito en donde el estudiante describe una experiencia exitosa de uso de fuentes de } \\
\text { rante: desarrollo de un test sobre una tarea que implica la consulta de fuentes de } \\
\text { spués: entrevista semiestructurada grabada. }\end{array}$ \\
\hline Análi & Triangl & ulación de la información recolectada en los tres momentos. \\
\hline & & Caracterización de la $\mathrm{Cl}$ \\
\hline Pobla & ión participante & $\begin{array}{l}60 \text { estudiantes universitarios que ingresaron en } 2009 \text { ॥ en la PUJ al programa de } \\
\text { Psicología. }\end{array}$ \\
\hline Preg & ta de investigación & ¿Cómo es la Cl en nuevos estudiantes universitarios? \\
\hline Objet & o general & $\begin{array}{l}\text { Caracterizar la Cl en estudiantes de primer semestre a partir de las prácticas que } \\
\text { establecen con las fuentes de información. }\end{array}$ \\
\hline Tesis & le trabajo & $\begin{array}{l}\text { La apropiación de significados culturales que, siendo parte de la relación y em- } \\
\text { poderamiento social del sujeto, inciden en su Cl. }\end{array}$ \\
\hline Tipo & estudio & $\begin{array}{l}\text { Estudio observacional descriptivo de tipo cualitativo (pertinente para experien- } \\
\text { cias de educación formal cuando se busca describir la estructura de un fenóme- } \\
\text { no particular, a fin de responder una pregunta delimitada y sistemática). }\end{array}$ \\
\hline Instru & nento & $\begin{array}{l}\text { Componente de recolección de datos: i) Cuestionario para la elaboración del per- } \\
\text { fil inicial; ii) Contrato (acuerdo): tarea que genera búsqueda de información con } \\
\text { pensamiento en voz alta; iii) Relato (manifiesto de sentido): generado a partir de } \\
\text { una entrevista semiestructurada. }\end{array}$ \\
\hline
\end{tabular}




\begin{tabular}{|l|l|} 
& $\begin{array}{l}\text { Componente de registro y análisis: ficha observacional para el registro e interpre- } \\
\text { tación de los datos y en directa relación con los instrumentos. }\end{array}$ \\
\hline $\begin{array}{l}\text { Registro y análisis de los } \\
\text { datos }\end{array}$ & $\begin{array}{l}\text { Sistema de registro cerrado y categorial descriptivo: implica la selección y el regis- } \\
\text { tro de patrones de comportamiento que dan cuenta de la cl. Para el registro de } \\
\text { datos se realizaron grabaciones y autoreportes. }\end{array}$ \\
\hline
\end{tabular}

Fuente: adaptado de Barbosa-Chacón et al. (2011: 8-14, 2012: 6-8)

En este proceso, y en particular para la definición de la tarea de búsqueda de información, se llevó a cabo una revisión de experiencias similares que permitió identificar una tarea relevante empleada por Hofer (2004) en el estudio sobre epistemologías personales. En la tarea propuesta por este autor se cumplen los criterios de Documentación, Validación e Interés Potencial (Marciales Vivas et al., 2010).

\section{El proceso de análisis}

La comprensión de las modalidades de la competencia generó la identificación de categorías y subcategorías para la observación de la CI. En el Cuadro 5 se presenta la definición de cada una de ellas según las diferentes modalidades (González Niño et al., 2013; Barbosa-Chacón et al., 2012).

Cuadro 5. Categorías y subcategorías estructurantes

\begin{tabular}{|c|c|c|c|}
\hline & & Categoría & Sub-categoría \\
\hline \multirow{3}{*}{ 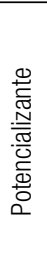 } & \multirow{3}{*}{ 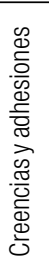 } & Naturaleza del conocimiento: creencias sobre qué & Certeza del conocimiento. \\
\hline & & $\begin{array}{l}\text { es el conocimiento. Va desde la visión del conoci- } \\
\text { miento como absoluto hacia una visión relativista o } \\
\text { contextual y constructivista. }\end{array}$ & Simplicidad del conocimiento. \\
\hline & & $\begin{array}{l}\text { Proceso para llegar a conocer: creencias construi- } \\
\text { das sobre el proceso por el cual se llega a conocer. } \\
\text { Incluye evaluación de la evidencia, el papel de la } \\
\text { autoridad y el proceso de justificación. }\end{array}$ & Justificación del conocimiento. \\
\hline 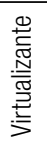 & 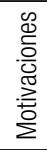 & \multicolumn{2}{|c|}{$\begin{array}{l}\text { Conjunto de razones que mueven a la acción, ubicadas en un continuo entre la acción mo- } \\
\text { tivada por el deber y la acción motivada por razones propias como la autodeterminación, la } \\
\text { curiosidad, el desafío o el esfuerzo. }\end{array}$} \\
\hline \multirow{2}{*}{ 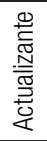 } & \multirow{2}{*}{ 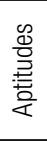 } & \multicolumn{2}{|c|}{$\begin{array}{l}\text { Saber: conocimientos que se tienen sobre el acceso, evaluación y uso de fuentes de informa- } \\
\text { ción y su utilidad en función de los objetivos académicos. }\end{array}$} \\
\hline & & \multicolumn{2}{|c|}{ Poder: recursos personales o contextuales con los que cuenta para la realización de una tarea. } \\
\hline 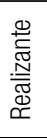 & 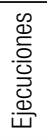 & \multicolumn{2}{|c|}{$\begin{array}{l}\text { Comportamientos que dan cuenta de las formas de acceder, evaluar y hacer uso de la infor- } \\
\text { mación, observados durante el desarrollo de una tarea, en un contexto situado de aprendizaje. }\end{array}$} \\
\hline
\end{tabular}

Fuente: adaptado de Barbosa-Chacón et al. (2012: 4-6) y González Niño et al. (2013: 116-118) 
En la investigación participaron 60 educandos del programa de Psicología, cuya edad promedio fue de 18.65 años. Las edades de estos estudiantes se distribuyeron según muestra el Gráfico 1, en donde se aprecia que un grupo significativo $(78.33 \%)$ registró edades que no superaban los 19 años.

Grafico 1. Distribución de las edades de los estudiantes de Psicología 2009 ॥

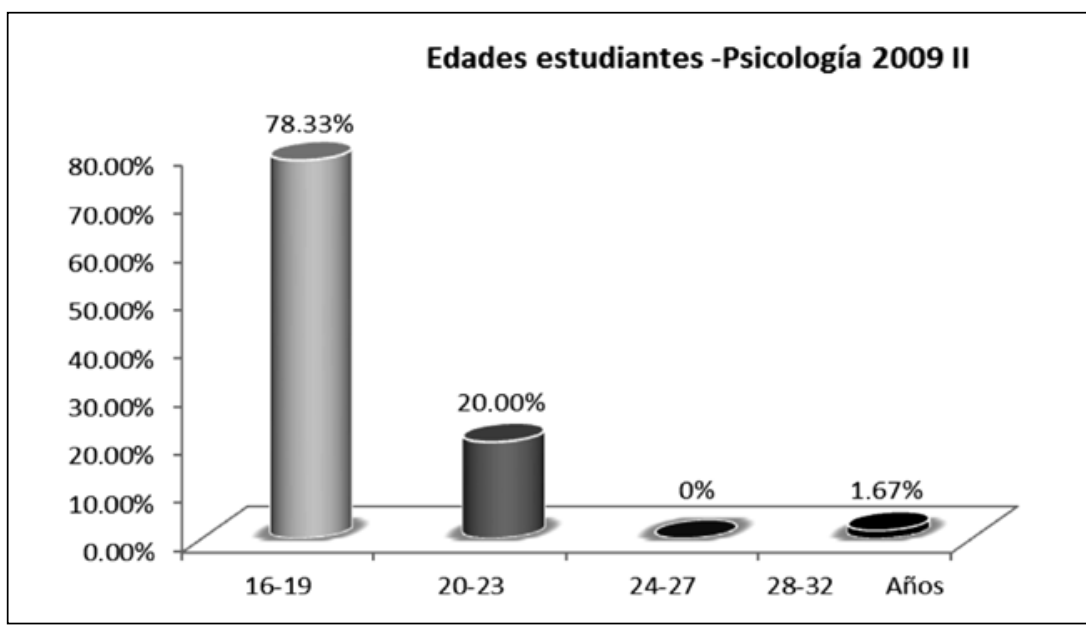

Fuente: construcción propia

El dato de la edad resulta relevante por la potencial incidencia que esta variable puede tener en el comportamiento informacional, máxime cuando se hace referencia a las prácticas habituales o preferidas de uso de fuentes de información, las cuales marcan una determinada temporalidad. Al respecto, el término "práctica" se refiere aquí a hacer algo en un contexto histórico y cultural que le da sentido, lo cual da cuenta del carácter situado de la competencia en la historia del sujeto (Wenger, McDermott \& Snyder, 2002).

Los referentes conceptuales y metodológicos presentados anteriormente configuraron el marco para la definición de los tres perfiles de la CI para los estudiantes, los cuales se describen a continuación.

\section{Los perfiles de la competencia informacional como producto de la caracterización}

Cada perfil se delimitó en función de las modalidades de competencia, reiterándose que la noción de perfil no es "estática". Así, en cada uno se identificaron creencias, motivaciones y habilidades potenciales que se actualizan en las formas de acceder, evaluar y hacer uso de la información. A continuación 
se exponen las características sobresalientes de cada perfil utilizando con este propósito cuadros que tienen en cuenta tanto las experiencias situadas de aprendizaje como algunos testimonios extraídos de los relatos de los estudiantes del programa.

Cuadro 6. Características del perfil recolector

\begin{tabular}{|c|c|}
\hline \multicolumn{2}{|r|}{ Perfil recolector } \\
\hline \multicolumn{2}{|r|}{ Experiencia situada de aprendizaje/Ejemplificación } \\
\hline $\begin{array}{l}\text { Confrontación entre informa- } \\
\text { ción entregada por el docente } \\
\text { y otras fuentes. }\end{array}$ & $\begin{array}{l}\text { "No, la verdad, me atengo sólo a lo que,... dicen las fotocopias." (R-6:11- } \\
(\mathrm{LR})^{7}\end{array}$ \\
\hline $\begin{array}{l}\text { Orientaciones de familiares } u \\
\text { otros sobre uso de fuentes de } \\
\text { información. }\end{array}$ & $\begin{array}{l}\text { "Mi papá, por lo menos, es una persona que lee mucho; pero yo no vivo con } \\
\text { él, entonces no tengo ese hábito, y mi hermano y mi mamá poco." (R-6:22- } \\
\text { LR) }\end{array}$ \\
\hline Exposiciones orales. & $\begin{array}{l}\text { "Al fin y al cabo (en) la exposición no me iban a preguntar ni de dónde saqué } \\
\text { la información ni nada, simplemente que dijera las cosas que la profesora } \\
\text { supiera, pues no había problema si me lo había dicho mi papá o lo había } \\
\text { buscado en alguna fuente; no era tan importante, ni siquiera en los trabajos, } \\
\text { no era tan importante, digamos, citar." (R-4:11-SP) }\end{array}$ \\
\hline Trabajos & $\begin{array}{l}\text { "Me limito a lo que está... A lo que contiene el tema. El ejemplo que les } \\
\text { estaba dando de finanzas. No puedo hacer grandes cambios... Hago lo que } \\
\text { tengo que hacer... y ya." (R-5:25-BT) }\end{array}$ \\
\hline \multicolumn{2}{|r|}{ Características correspondientes } \\
\hline \multicolumn{2}{|c|}{$\begin{array}{l}\text { - Presencia de creencias sobre la existencia de la verdad en alguna fuente de información externa. } \\
\text { - Internet se valora como herramienta útil porque alli "se encuentra todo". } \\
\text { - Recolectar mucha información y poseerla son dos criterios importantes. } \\
\text { - Son escasas las experiencias familiares o escolares orientadoras de las prácticas de uso de las fuentes de } \\
\text { información. } \\
\text { - Los aprendizajes sobre el acceso, la evaluación y el uso de fuentes de información se derivan fundamental- } \\
\text { mente del ensayo y el error. } \\
\text { - Prevalecen en el tiempo aquellas acciones que hayan conducido a resultados académicos "exitosos" y } \\
\text { cuyo criterio de éxito es la "calificación". } \\
\text { - La motivación para la realización de tareas académicas que impliquen el acceso, evaluación y uso de fuen- } \\
\text { tes de información está sustentada fundamentalmente en la "obligación" o "el deber". }\end{array}$} \\
\hline
\end{tabular}

Fuente: adaptado de Castañeda-Peña et al. (2010: 205) y Marciales Vivas et al. (2010: 14-17)

Se podrá observar que tanto las motivaciones como las experiencias de vida que inciden en la CI del sujeto ubicado en el perfil recolector cambian sustancialmente frente al perfil verificador.

7 El extracto codificado como (R-6:11-LR) significa: $R$ indica la fuente del dato, para el caso el relato; 6:11 indica el número del relato y el número que codifica la parte del relato; $L R$ es la identidad anónima del estudiante participante. 
Cuadro 7. Características del perfil verificador

\begin{tabular}{|c|c|}
\hline \multicolumn{2}{|r|}{ Perfil verificador } \\
\hline \multicolumn{2}{|r|}{ Experiencia situada de aprendizaje/Ejemplificación } \\
\hline $\begin{array}{l}\text { La realización de ensa- } \\
\text { yos como tarea que fa- } \\
\text { vorece la valoración de } \\
\text { fuentes de información. }\end{array}$ & $\begin{array}{l}\text { "Toca tomar varias fuentes de distintas fuentes que tienen varios puntos de vista, } \\
\text { sobre todo en ese tipo de ensayo que no es explicativo sino argumentativo, que uno } \\
\text { puede poner varios puntos de vista..., pues un problema se encuentra a los dos } \\
\text { para que al final tú saques una conclusión de eso." (R-3:13-MPR) }\end{array}$ \\
\hline $\begin{array}{l}\text { Los límites de búsque- } \\
\text { da de fuentes desde } \\
\text { la relación acumula- } \\
\text { ción-apreciación de la } \\
\text { utilidad de la fuente. }\end{array}$ & $\begin{array}{l}\text { "Hasta encontrar unas fuentes muy buenas porque en Google también hay e } \\
\text { books. } 0 \text { sea, hay libros que tú puedes leer dentro de Google, entonces es mu } \\
\text { bueno si tú encuentras esas bases de datos, si tú encuentras artículos sobre } \\
\text { autor, digamos en el que te estás basando, y eso es muy bueno..." (R-2:12-DR) }\end{array}$ \\
\hline Jso d & le \\
\hline $\begin{array}{l}\text { La } m \\
\text { desar }\end{array}$ & $\begin{array}{l}\text { "Tú primero lo haces con la pasión de investigar, como, digamos jay, para mañana } \\
\text { tengo que hacer un trabajo, qué pereza! Cuando no me gusta, pero jay, mañana el } \\
\text { trabajo de filosofía, entonces esta noche tengo que investigar de Sócrates!, enton- } \\
\text { ces es como lo que a uno le apasiona y es chévere eso, que uno lo hace con gusto, } \\
\text { con amor, de todas maneras eso siempre se refleja." (R-1:31-NJ) }\end{array}$ \\
\hline \multicolumn{2}{|r|}{ Características correspondientes } \\
\hline \multicolumn{2}{|c|}{$\begin{array}{l}\text { - Se cree que el conocimiento es relativo, contextual y obedece a la perspectiva desde la que cual se aborda. } \\
\text { - La búsqueda de fuentes de información se realiza empleando principalmente bases de datos, bibliotecas y } \\
\text { textos web sobre investigaciones; fuentes que son verificadas a través del análisis de la puesta en relación } \\
\text { con otras. } \\
\text { - El uso de buscadores (Google por excelencia) obedece a dos razones: i) limitaciones de tiempo y ii) utilidad } \\
\text { para formarse un esquema general del tema por consultar. } \\
\text { - La motivación hacia el uso de las fuentes está sustentada fundamentalmente en la posibilidad de aprender } \\
\text { algo nuevo que aporte a la propia formación. }\end{array}$} \\
\hline
\end{tabular}

Fuente: adaptado de Castañeda-Peña et al. (2010: 205) y Marciales Vivas et al. (2010: 17-19)

Se podrá observar el protagonismo del sujeto ubicado en el último de los perfiles (perfil reflexivo) y, en particular, las justificaciones de su comportamiento informacional en relación con su propio aprendizaje.

Cuadro 8. Características del perfil reflexivo

\begin{tabular}{|l|l|}
\hline \multicolumn{1}{|c|}{ Perfil reflexivo } \\
\hline \multicolumn{1}{|c|}{ Experiencia situada de aprendizaje/Ejemplificación } \\
\hline $\begin{array}{l}\text { Organización } \\
\text { de búsqueda de } \\
\text { información. }\end{array}$ & $\begin{array}{l}\text { "Uno empieza con ideas demasiado amplias, por ejemplo en eso, en un proyecto de in- } \\
\text { dagación, uno siempre empieza con ideas muy amplias, con ideas muy amplias... como } \\
\text { muy soñadas, como por decirlo así, como ay qué chévere saber sobre tal y tal cosa, pero } \\
\text { entonces es ahí donde uno empieza a mirar sí de eso que quieres saber, qué información } \\
\text { hay, qué podemos investigar, qué podemos sacar, cómo podemos trabajar con eso." (R- } \\
\text { 4:24-SP) }\end{array}$ \\
\hline
\end{tabular}




\begin{tabular}{l|l|}
\hline $\begin{array}{l}\text { Elaboración de } \\
\text { ensayos acadé- } \\
\text { micos. }\end{array}$ & $\begin{array}{l}\text { "Yo vuelvo y reviso lo que acabo de escribir y comienzo a relacionarlo, a entender qué fue } \\
\text { lo que quise decir cuando escribí esa idea y luego ahí sí comienzo a escribir el ensayo, pe- } \\
\text { ro no relacionado, colocando exactamente la idea que escribí, sino viendo qué coherencia } \\
\text { tiene, o sea, que el resto de personas lo entiendan y que yo lo entienda... La coherencia } \\
\text { que tengan estas ideas... y también colocando mi punto de vista." (R-5:21-BT) }\end{array}$ \\
$\qquad$ \\
Características correspondientes \\
\hline $\begin{array}{l}\text { - Tendencia a la formulación de preguntas propias previas a la realización de búsquedas de fuentes de infor- } \\
\text { mación. }\end{array}$ \\
- Planificación ante el desarrollo de búsquedas. \\
- Las prácticas aluden, especialmente, a que los educandos se asumen como constructores activos de in- \\
afrontar posiciones críticas frente a la información, independiente de la autoridad de la misma. \\
- Lo importante, más que las tareas académicas por sí mismas, es el aporte que éstas representan para el \\
proyecto de vida, así como la riqueza que representa todo conocimiento nuevo.
\end{tabular}

Fuente: adaptado de Castañeda-Peña et al. (2010: 205) y Marciales Vivas et al. (2010: 20-22)

Después de determinar los tres perfiles se identificó que el recolector tiende a ser representativo de los estudiantes que ingresan a la universidad, en tanto que el perfil reflexivo es el más escaso. Esta realidad fue palpable en los estudiantes del programa en donde sólo uno de ellos fue ubicado en el perfil reflexivo, el cual, por la descripción ya dada, se comprende como una realización de la CI más significativa y provechosa. La distribución de los perfiles se aprecia en el Gráfico 2.

Gráfico 2. Distribución de los perfiles de competencia informacional

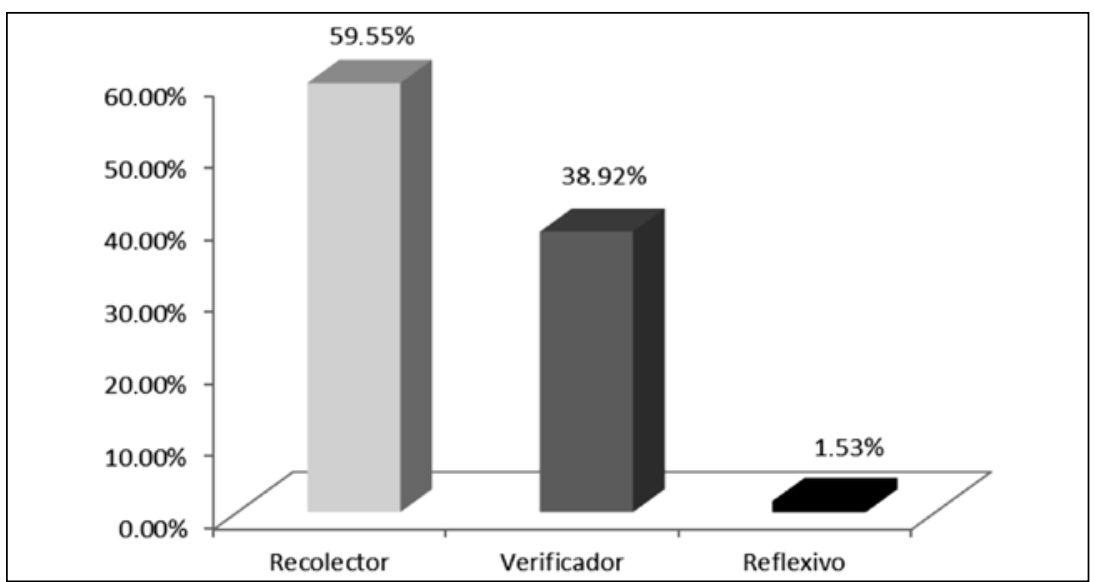

Fuente: construcción propia

Teniendo en cuenta la anterior realidad, se generan preguntas y compromisos educativos que atañen a toda disciplina o área de formación, pero que 
confrontan de manera directa a la ciencia de la información. Por ello, a continuación se enfatizan algunos de los retos que se derivan de la investigación y que son base para la formulación de gestiones de intervención en el contexto universitario.

\section{¿QUÉ RETOS PLANTEA LA INVESTIGACIÓN A LA FORMACIÓN DE USUARIOS DE INFORMACIÓN UNIVERSITARIOS? AlgunOS COMPROMISOS PARA LA CUALIFICACIÓN DE NUEVOS ESTUDIANTES}

Son multidimensionales tanto los aportes como los retos que desde la investigación se están haciendo al estudio de las CI, cuyo desarrollo exige una estrecha relación de colaboración entre las diferentes instancias responsables de los procesos formativos. Al respecto vale la pena interrogarse sobre las funciones complementarias que los profesionales de la ciencia de la información deben asumir para apoyar a los educandos en la sociedad de la información, en la cual ser competente informacionalmente tiene implicaciones académicas, sociales, económicas y políticas; implicaciones que, como afirma Garmendia Bonilla (2005), forman parte de una cultura informacional necesaria para el desempeño en el mundo actual.

Algunos de los retos que surgen de las experiencias de investigación y que es pertinente enunciar aquí son aquellos que ponen en conflicto la relación entre sociedad de la información y el proceso de construcción de conocimiento. Ellos son: i) En cuanto al desarraigo de la información. Se plantea como reto la revalorización del concepto de autoría de las fuentes, movimiento que se contrapone a la irrelevancia que ésta parecería tener, en donde el año de publicación y el autor parecerían ser "fácilmente" sustituibles por la fecha de consulta y la dirección web correspondiente; ii) En relación con el tratamiento efectivo con el hipertexto. En esto se dista de acciones de jerarquía y centralidad y exigen el desarrollo de competencias para leer lateralmente (Fainholc, 2004; Eshet-Alkalai, 2004) y construir mapas de relaciones entre fuentes de información, relaciones que emergen a partir de la perspectiva de un lector-autor, es decir, se configura como prosumidor (Corona Rodríguez, 2012; Giurgiu \& Barsan, 2008); iii) Lo relativo a la sobrecarga de información. Exige el desarrollo de gestiones con criterios pertinentes para filtrar información de rigor (Valverde Berrocoso y Garrido Arroyo, 2005; Vonderwell, 2003).

Los retos planteados a los jóvenes como usuarios de la información no deberían ser un problema si se les asume como nativos digitales dados sus atributos distinguibles para aprender y comunicarse (Cabra-Torres y Marciales Vivas, 2009; Prensky, 2001), pero los resultados de investigación han ido 
generando dudas debido a la presencia de problemas o necesidades, como los que se enuncian en el Cuadro 9.

Cuadro 9. Problemas o necesidades que emergen desde experiencias investigativas

\begin{tabular}{|c|c|c|}
\hline & & Necesidades/Problemas \\
\hline \multirow{8}{*}{ 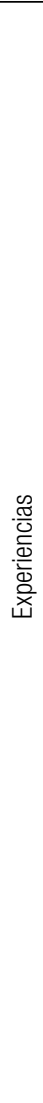 } & 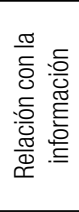 & $\begin{array}{l}\text { La caracterización de las } \mathrm{Cl} \text { muestra un dominio del perfil recolector (perfil que requiere } \\
\text { de mayor apoyo educativo) y una marcada ausencia del perfil reflexivo (perfil deseable } \\
\text { académicamente). De igual manera emergen las necesidades de procesos de formación } \\
\text { intencionados y contextualizados para contribuir con el desarrollo de habilidades para una } \\
\text { efectiva relación sujeto-fuentes de información (Castañeda et al., 2010; Barbosa-Chacón } \\
\text { et al., 2012). }\end{array}$ \\
\hline & \multirow{4}{*}{ 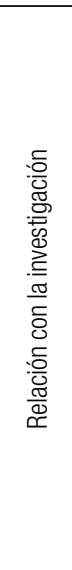 } & $\begin{array}{l}\text { Existen dificultades para la comprensión del horizonte de trabajos de corte investigativo, } \\
\text { en particular cuando no se ha definido bien el problema o la pregunta de indagación. Esto } \\
\text { conlleva a interrogantes del tipo ¿cómo seleccionar las ideas más importantes, cuando se } \\
\text { ha encontrado demasiada información?, ¿cómo estar seguro de que lo que se selecciona } \\
\text { es lo más importante? (Alzate y Peña, 2010). }\end{array}$ \\
\hline & & $\begin{array}{l}\text { Las habilidades de orden instrumental, investigativo y estratégico dan cuenta de una ele- } \\
\text { vada prevalencia de desarrollo de las primeras sobre las otras dos, que no se desarrollan } \\
\text { por experiencia sino en razón de acciones formales y orientadas con tal propósito (Van } \\
\text { Deursen \& Van Dijk, 2008). }\end{array}$ \\
\hline & & $\begin{array}{l}\text { Existen insuficiencias asociadas con las competencias investigativas en los procesos de } \\
\text { formación. Esto muestra la falta de sistematización en procesos educativos relacionados } \\
\text { con la metodología de la investigación; problemática que se evidencia en la inadecuada } \\
\text { preparación de los estudiantes al terminar los estudios (Álvarez Villar, Orozco Hechavarria } \\
\text { y Gutiérrez Sánchez, 2011). }\end{array}$ \\
\hline & & $\begin{array}{l}\text { El desarrollo del espíritu investigativo no siempre suele estar en armonía con la capacidad } \\
\text { para leer, interpretar y escribir textos académicos (Alzate y Peña, 2010). }\end{array}$ \\
\hline & \multirow{3}{*}{ 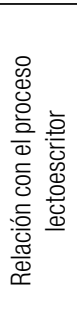 } & $\begin{array}{l}\text { Se reportan dificultades para comprender un texto, resumirlo o juzgarlo críticamente, a } \\
\text { ello se suman problemas en la composición de ensayos y artículos de carácter argumenta- } \\
\text { tivo (González Moreno, 2012; Cardinale, 2007). }\end{array}$ \\
\hline & & $\begin{array}{l}\text { Existen evidencias de niveles bajos en cuanto a la planificación al elaborar ensayos, en } \\
\text { la reorganización de ideas e integración de la escritura en los mismos (Ochoa Angrino y } \\
\text { Aragón Espinosa, 2007). }\end{array}$ \\
\hline & & $\begin{array}{l}\text { Las habilidades para el uso de textos digitales muestran una tendencia a generalizar las } \\
\text { habilidades desarrolladas con textos impresos, aun cuando no operan de igual forma (Al- } \\
\text { mind \& Ingwersen, 1997; Eveland \& Dunwoody, 2001; Fitzgibbons, 2008). }\end{array}$ \\
\hline
\end{tabular}

Fuente: construcción propia

Ante las problemáticas y necesidades planteadas resalta el compromiso para los agentes educativos universitarios no sólo en materia de desarrollo de CI, sino también de competencias investigativas y de lectoescritura. Asumir esta meta exige el diseño de propuestas formativas que garanticen significativos niveles de apropiación, empoderamiento y sostenibilidad en los estudiantes; es decir, se requiere de nuevos y adecuados métodos y didácticas que sean experimentadas al inicio de los programas académicos (Batellino y Lissera, 2006). En tal sentido, y como una alternativa para aproximarse al 
logro de los niveles antes enunciados, es importante que las propuestas de formación se soporten en referentes teóricos y procedimentales como los que se plantean en el Cuadro 10.

Cuadro 10. Referentes teóricos y procedimentales que sirven de apoyo a procesos formativos

\begin{tabular}{|c|c|c|}
\hline & Descripción/Horizonte de acción \\
\hline \multirow{7}{*}{ 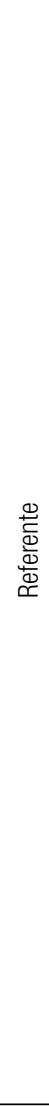 } & Trabajo independiente & $\begin{array}{l}\text { Se busca que los estudiantes aprendan por sí mismos, bajo una perspectiva } \\
\text { que garantice la motivación ante la realización de sus trabajos. Esta estra- } \\
\text { tegia busca disminuir la dependencia al docente (Rodríguez Cobián, 2009; } \\
\text { Broad, 2006; González Jiménez, 2010). }\end{array}$ \\
\hline & Aprender haciendo & $\begin{array}{l}\text { Con base en la premisa de que el aprendizaje trascendente se hace desde } \\
\text { la praxis conectado a situaciones reales, por ello los individuos aprenden a } \\
\text { medida que desarrollan actividades concertadas, valoran lo que aprenden y } \\
\text { mejoran sus prácticas (Raij, 2007; De la Orden, 2007; Marcos, 2011). }\end{array}$ \\
\hline & $\begin{array}{l}\text { Aprender entre pares } 0 \\
\text { iguales }\end{array}$ & $\begin{array}{l}\text { Estrategia que permite reconocer que apoyarse mutuamente durante el pro- } \\
\text { ceso de aprendizaje es una buena manera de aprender y apoyar el desarro- } \\
\text { Ilo integral (Topping, 1996; Griffin \& Griffin, 1998; Newman, Griffin \& Cole, } \\
\text { 1998; Ferrer, 2003; Durán Gisbert y Huerta Córdoba, 2008; Alzate y Peña, } \\
\text { 2010). }\end{array}$ \\
\hline & Trabajo por problemas & $\begin{array}{l}\text { El propósito es aprender en torno a la solución de problemas asociados a la } \\
\text { disciplina de estudio, utilizando para ello fuentes de rigor. Esto exige asesoría } \\
\text { y acompañamiento que garanticen que los estudiantes sean capaces de apli- } \\
\text { car el conocimiento para resolver tales problemas (Bernhard, 2002; Dochy, } \\
\text { Segers \& Dierick et al., 2002; Serrano de Moreno y Peña González, 2003). } \\
\end{array}$ \\
\hline & $\begin{array}{l}\text { Lectura crítica y } \\
\text { reflexiva }\end{array}$ & $\begin{array}{l}\text { Vista como una manera de acceder a procesos cognitivos complejos y como } \\
\text { mecanismo de apropiación conceptual, así como de relación con el queha- } \\
\text { cer práctico (Marciales Vivas, 2003; González Moreno, 2012). }\end{array}$ \\
\hline & $\begin{array}{l}\text { Materiales de apoyo al } \\
\text { aprendizaje }\end{array}$ & $\begin{array}{l}\text { Contar con materiales cuyos contenidos y actividades sean no lineales y que } \\
\text { además de guiar al educando lo reten al aprendizaje; que consideren las ca- } \\
\text { racterísticas particulares de la población objetivo y las exigencias de la mo- } \\
\text { dalidad educativa y del programa académico (principios y perfiles) (Gualdrón } \\
\text { y Rey, 2002; Penzo et al., 2010). }\end{array}$ \\
\hline & $\begin{array}{l}\text { Trabajo interdisciplinar } \\
\text { y colaborativo }\end{array}$ & $\begin{array}{l}\text { Implica gestión educativa entre agentes educativos de las distintas instan- } \\
\text { cias y áreas de formación profesional. Ello implica la interrelación de proce- } \\
\text { sos de aprendizaje, enseñanza, investigación y contexto tanto social como } \\
\text { organizacional (Bernhard, 2002; Uribe Tirado, 2010; Marciales Vivas et al., } \\
\text { 2013). }\end{array}$ \\
\hline
\end{tabular}

Fuente: construcción propia

En consecuencia, en la siguiente sección se socializa una experiencia conjunta entre docentes y profesionales de la ciencias de la información, quienes, con el propósito de apoyar la cualificación inicial de estudiantes universitarios, tomaron como base de intervención los compromisos relacionados con el aprendizaje de usuarios de información y los referentes teóricos y procedimentales en materia de diseño y desarrollo de propuestas de formación antes planteados. Se trata de una propuesta que integra a la formación profesional aportes de la bi- 
bliotecología y que toma en cuenta las características propias del currículo del programa de Psicología de la PUJ como contexto situado de aprendizaje.

\section{¿CÓMO APOYAR EL APRENDIZAJE DE USUARIOS DE INFORMACIÓN EN LA universidad? Una apuesta del Programa de Psicología de la PUJ}

Lo documentado hasta ahora evidencia la importancia que debe darse al contexto de intervención y, en especial, a las necesidades y problemas de la población objetivo. En concordancia con esto, y con la ubicación en el contexto PUJ, la investigación identificó elementos propios del perfil de ingreso a la universidad como recurso para la determinación de necesidades de formación iniciales, a fin de planear estrategias de apoyo para cualificar su desempeño académico. A continuación se exponen algunas de las problemáticas que se evidenciaron a partir de los relatos de los estudiantes de primer semestre del programa en 2009 II, quienes participaron en la experiencia de caracterización descrita.

\section{Cuadro 11. Problemáticas manifiestas en el estudio de caracterización}

\begin{tabular}{|c|c|c|}
\hline & & Ejemplificación (Relatos) \\
\hline \multirow{5}{*}{ 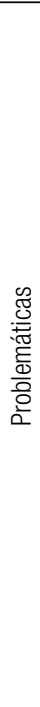 } & $\begin{array}{l}\text { Falta de claridad sobre } \\
\text { el sentido de la cons- } \\
\text { trucción de ensayos. }\end{array}$ & $\begin{array}{l}\text { "En la Universidad yo sí he mirado ese cambio y es un cambio radical, por lo } \\
\text { menos desde mi colegio porque... me dejaban trabajos y... ensayos, pero ni } \\
\text { los profesores sabían qué era un ensayo... ni yo sabía qué era un ensayo... } \\
\text { entonces uno iba a Wikipedia y copiaba y pegaba y sí, puede que aprendía } \\
\text { pero el trabajo no era lo que... el profesor quería." (NJ) }\end{array}$ \\
\hline & $\begin{array}{l}\text { Adhesión a escenarios } \\
\text { exclusivos de búsque- } \\
\text { da de información. }\end{array}$ & $\begin{array}{l}\text { "No mira que desde el colegio era más Internet y por eso es que soy un poco } \\
\text { ágil a la hora de buscar cosas y además pues con los puntos más, pues con } \\
\text { el Internet, pero generalmente libros no." (NJ) }\end{array}$ \\
\hline & $\begin{array}{l}\text { Variabilidad en cuanto } \\
\text { al nivel de profundi- } \\
\text { zación y extensión de } \\
\text { trabajos. }\end{array}$ & $\begin{array}{l}\text { "Bueno, pues yo profundizaba más, generalmente mi trabajo era largo y los } \\
\text { de mis compañeros eran muy cortos y también se, pues se contentaban con } \\
\text { una sola cosa, pues desde que hicieran el trabajo, ya listo, pero pues de } \\
\text { pronto yo lo hacía un poquito más larguito o así." (NJ) }\end{array}$ \\
\hline & $\begin{array}{l}\text { Incidencia de la mo- } \\
\text { tivación ante el desa- } \\
\text { rrollo de tareas acadé- } \\
\text { micas. }\end{array}$ & $\begin{array}{l}\text { "Pero puede que me, pero es distinto, puede que un ensayo que me guste } \\
\text { puede que me demore muy poquito tiempo y que en uno que no me guste } \\
\text { me demore mucho porque a mí, da pereza, entonces uno va y bueno, busca, } \\
\text { entonces le da pereza leer porque no le gusta el tema, eso sí." (MP) }\end{array}$ \\
\hline & $\begin{array}{l}\text { Indecisión en cuanto a } \\
\text { criterios de valoración } \\
\text { de la información (in- } \\
\text { clusión y exclusión). }\end{array}$ & $\begin{array}{l}\text { "Pero cuando consulto, todo me parece importante, entonces me cuesta co- } \\
\text { mo delimitar qué es lo que tengo que poner..." (BH) }\end{array}$ \\
\hline
\end{tabular}

Fuente: construcción propia

Situaciones como las anteriores motivaron a los agentes educativos del programa de Psicología de la PUJ a formular algunas gestiones encaminadas 
a contribuir con el desarrollo de las competencias informacionales, investigativas y lectoescriturales de los alumnos. Una de estas gestiones es la experiencia pedagógica denominada Proyecto de Indagación (PRIN), en el cual se formaron los educandos que participaron en el estudio de caracterización.

\section{El proyecto PRIN}

En la Facultad de Psicología los agentes educativos tienen claro que una apropiación sólida de la lengua escrita es un factor clave para el fortalecimiento de las CI y un insumo más para el financiamiento de la comunidad académica. Los procesos de lectura y escritura, además de ser básicos para apoyar el desarrollo del pensamiento crítico y reflexivo, constituyen una herramienta fundamental para el aprendizaje, la investigación y la comunicación de ideas; inciden además en las maneras de pensar, de sentir y de aprender. En todo ello la pregunta juega un papel preponderante porque es la fuerza que moviliza la búsqueda de conocimiento (Peña, 2009).

$\mathrm{El}$ anterior marco es contemplado en el PRIN, iniciativa que se ha desarrollado en la Facultad de Psicología desde el año 2006 con los estudiantes de reciente ingreso; su objetivo fundamental ha sido promover en los estudiantes la importancia de la pregunta y la indagación en la producción de conocimiento, en este caso, de naturaleza psicológica.

A través del PRIN se pretende desarrollar en los estudiantes una actitud positiva frente a la investigación, generar un espacio de articulación de diferentes perspectivas de la psicología en torno a núcleos problémicos y potenciar el desarrollo cognitivo en términos de argumentación y de apropiación del universo simbólico-cultural de la psicología, mediante la producción de textos escritos (Alzate y Peña, 2010; Marciales Vivas et al., 2010).

Las anteriores apuestas se materializan a través de una estrategia que conjuga varios elementos: i) el acompañamiento de un profesor; ii) el trabajo en parejas y en grupo fundamentado en el aprendizaje cooperativo; iii) la orientación del trabajo a partir de guías que actúan como mediaciones sobre los géneros académicos seleccionados (resumen, reseña y ensayo); iv) la sincronización entre espacios de acompañamiento (talleres y tutorías).

La apuesta didáctica y pedagógica está del lado de la evaluación permanente como condición del acompañamiento, gracias a la participación y reconocimiento de tres agentes educativos principales: i) el profesor, que actúa como "experto" y cuya función es definir los lineamientos generales del trabajo; ii) el tutor, un estudiante que realizó el PRIN en otro momento y que trabaja de acuerdo con los lineamientos del profesor sirviendo como "enlace" entre él y los estudiantes a modo de "novato avanzado" y iii) el grupo de 
estudiantes, entre quienes se intercambia y valora de manera permanente el trabajo realizado.

Para ahondar en el horizonte del PRIN se enuncian a continuación sus fases de desarrollo, el taller sobre CI y algunas reflexiones y valoraciones sobre la práctica.

\section{Las fases del proyecto PRIN}

En el Cuadro 12 se describen, en forma resumida, las actividades que se realizan en cada una de las fases del PRIN con su respectivo producto o evidencia principal.

Cuadro 12. Fases del proyecto PRIN

\begin{tabular}{|c|c|}
\hline \multicolumn{2}{|r|}{ Proyecto PRIN } \\
\hline Fase & Experiencias de enseñanza, aprendizaje y evaluación \\
\hline \multirow[t]{2}{*}{ 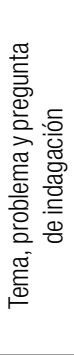 } & $\begin{array}{l}\text { - Cada profesor desarrolla una tutoría individual con sus estudiantes para ubicar el tema y el } \\
\text { problema de indagación. } \\
\text { - El profesor y el tutor sugieren fuentes de información para ampliar la comprensión del proble- } \\
\text { ma y reformular la pregunta de indagación. } \\
\text { - Los estudiantes revisan la bibliografía básica e identifican las ideas-fuerza y los aspectos más } \\
\text { significativos para plantear una pregunta relacionada con las discusiones psicológicas. } \\
\text { - Los profesores realizan una tutoría para valorar (revisar y aportar) la selección del tema/pro- } \\
\text { blema y la formulación de su pregunta. }\end{array}$ \\
\hline & $\begin{array}{l}\text { Producto de la fase: un escrito exploratorio en el que se sustenta la elección del problema de } \\
\text { indagación. }\end{array}$ \\
\hline \multirow{2}{*}{ 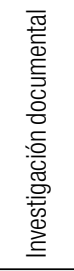 } & $\begin{array}{l}\text { - Los estudiantes revisan la bibliografía recomendada y buscan otras fuentes. } \\
\text { - Los registros de información se hacen en forma de fichas bibliográficas y reseñas. } \\
\text { - Los tutores apoyan a los estudiantes en la búsqueda bibliográfica, el análisis e interpretación } \\
\text { de los textos consultados y la producción escrita de las reseñas. } \\
\text { - En el contexto de esta fase se realiza un taller de Cl. }\end{array}$ \\
\hline & $\begin{array}{l}\text { Producto de la fase: documentación de reseñas como base para elaborar el marco de referencia } \\
\text { del ensayo final. }\end{array}$ \\
\hline \multirow{2}{*}{ 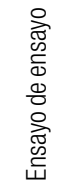 } & $\begin{array}{l}\text { Con base en el taller y las orientaciones de los profesores y los tutores, los estudiantes desarro- } \\
\text { Ilan el plan del ensayo y elaboran un primer borrador del texto. }\end{array}$ \\
\hline & Producto de la fase: plan de ensayo y primer borrador de texto. \\
\hline \multirow[t]{2}{*}{ 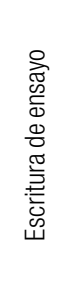 } & $\begin{array}{l}\text { - El profesor revisa el plan y el borrador del ensayo y realiza una tutoría, en la cual discute el } \\
\text { planteamiento de la tesis, la pertinencia de los argumentos y su relación con posiciones teóri- } \\
\text { cas de la Psicología. } \\
\text { - El estudiante revisa el ensayo con base en las observaciones, clarifica la tesis y fortalece sus } \\
\text { argumentos. } \\
\text { - El tutor apoya al estudiante en la revisión del texto. El profesor evalúa el ensayo final con base } \\
\text { en criterios previamente construidos y conocidos por los estudiantes. }\end{array}$ \\
\hline & Producto de la fase: ensayo. \\
\hline
\end{tabular}




\begin{tabular}{|c|c|}
\hline \multirow[t]{2}{*}{ 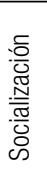 } & $\begin{array}{l}\text { - Por grupos de tutoría se exponen los ensayos, con el fin de compartirlos y enriquecer las dis- } \\
\text { cusiones propias del campo de formación. } \\
\text { - Se selecciona un trabajo por cada grupo para ser presentado en el coloquio que se realiza al } \\
\text { final del periodo académico y al cual asisten estudiantes y profesores de primer semestre. }\end{array}$ \\
\hline & Producto de la fase: interacción. \\
\hline
\end{tabular}

Fuente: adaptado de Marciales Vivas et al. (2010: 23-31) y Alzate y Peña (2010: 127-136)

\section{El Taller de Competencias Informacionales (TCI)}

La producción de textos propios a partir de fuentes documentales es una de las tareas comunes de los estudiantes universitarios; labor que en los términos de Spivey \& King (1989) y Vásquez (2008) se denomina "síntesis discursiva", en donde el escritor reelabora el material original y lo transforma para crear un nuevo texto. Como se pudo apreciar en el Cuadro 12, producir textos propios es una labor que el proyecto PRIN contempla en sus dos primeras fases. Para ello se hace necesaria una consulta bibliográfica, condensar un volumen considerable de información, organizarla en una nueva estructura, establecer relaciones intertextuales, comparar posturas y, por último, sintetizar lo hallado en un texto coherente (Alzate y Peña, 2010; Marciales Vivas et al., 2010).

Como se manifestó antes, en la producción de textos se evidencia que, detrás de los problemas de escritura, se ocultan deficiencias en la lectura, entendida integralmente como una construcción social en la que intervienen no sólo el texto y el lector sino también los espacios institucionales, los tiempos y lugares, las prácticas y las personas. El anterior panorama justifica la presencia del TCI, con el cual se proyecta el logro de dos propósitos: por un lado, apoyar el desarrollo de competencias lectoras e informacionales con el fin de aprovechar de mejor manera los recursos y servicios de las bibliotecas y, por otro, contribuir a la motivación por la lectura, al desarrollo del espíritu investigativo y al aprendizaje independiente. En esencia, el TCI es una estrategia que surge como una necesidad inherente al proceso investigativo y como un trabajo conjunto con el servicio de formación de usuarios de información de la PUJ.

El desarrollo del TCI requiere de un equipo de trabajo conocedor de los contextos y necesidades particulares de los proyectos de los educandos (temas y problemas de indagación) como insumo para la preparación del taller (actividades y ejercicios prácticos). Esto contribuye a que el TCI sea una actividad significativa y motivadora. El eje de las actividades es la búsqueda y selección de información, lo cual implica identificar los mecanismos pertinentes para acceder a ella, evaluarla y utilizarla críticamente. Como producto 
concreto se elabora una bibliografía cuya actualidad y pertinencia se discute con profesores y tutores. En esencia, con el TCI se busca posicionar la biblioteca como banco de información, lugar de estudio e investigación (Alzate y Peña, 2010; Marciales Vivas et al., 2010).

\section{Valoraciones sobre la experiencia PRIN}

- Sobre los contenidos: i) en un comienzo los temas eran planteados por los estudiantes desde sus propios intereses; luego, al pasar por los llamados campos de indagación, que respondían a los intereses y pericias de los profesores responsables, se estableció un menú o temario definido por el equipo de profesores en primer semestre a partir de los contenidos de su asignatura; ii) como elemento de fortalecimiento, se desarrolló un portal web que funciona a modo de repositorio y gestor de contenidos. La idea con este portal es brindar, por un lado, la oportunidad de acceder y conocer con más detalle el proyecto; por otro, ofrecer un escenario para el registro del acompañamiento realizado a los estudiantes cada semestre. De igual manera, se ha implementado el uso de Facebook como complemento por su facilidad, usabilidad y penetración entre los estudiantes.

- Sobre la interacción. La forma en que se han organizado los momentos de relación entre agentes educativos ha permitido promover el fortalecimiento de habilidades personales e interpersonales (razonamiento, toma de posiciones, colaboración), logrando así trascender dimensiones tradicionales e instrumentales relacionadas con el aprendizaje.

- Sobre el impacto en los estudiantes. Algunos cambios se observan en las actitudes y en las representaciones que tienen los estudiantes de Psicología sobre la experiencia educativa, en especial sobre la forma de relacionarse con la información. Los educandos: i) han empezado a hacer un mejor uso de la información, lo cual se evidencia en la cantidad, calidad, pertinencia y variedad de fuentes consultadas y en la incorporación de revistas especializadas adicionales a la consulta de libros; ii) han ganado en autonomía, pues se observa que por cuenta propia regresan a la biblioteca para efectuar nuevas consultas; iii) han logrado incorporar y diferenciar las características de escritos académicos propios de la disciplina de formación; iv) han afirmado que el PRIN les permite ganar una mayor conciencia sobre el valor que tiene la información como recurso para el trabajo investigativo, las responsabilidades que implica su uso y el poder que encierra para cuestionar las creencias y las verdades que se tenían por ciertas. 
Otras reflexiones y valoraciones sobre la experiencia PRIN pueden ser observadas en Alzate y Peña (2010) y Marciales Vivas et al. (2010).

\section{¿CUÁL ES LA REFLEXIÓN Y DISCUSIÓN FINAL?}

Las competencias informacionales, como conjunto de creencias, motivaciones y habilidades construidas en la historia de vida de los sujetos, ha de ser comprendida y desarrollada en contextos situados de aprendizaje desde aproximaciones comprehensivas y complejizadoras que den cuenta de su relación con factores familiares, escolares, sociales, culturales y económicos.

La caracterización presentada, además de establecer perfiles de la CI, busca llamar la atención sobre las necesidades y problemas de los educandos para afrontar los retos académicos al momento de su ingreso a la universidad. Por tanto, los perfiles se proponen como pre-textos para aportar a la reflexión de los agentes educativos sobre las acciones que habrían de ser generadas, a fin de contribuir para que el acceso a la educación superior sea realmente una condición que contribuya al desarrollo personal y social y no se configure como factor de frustración.

Teniendo en cuenta el interés de las instituciones educativas y de los entes gubernamentales acerca de la generación de condiciones de equidad para el acceso a este nivel de formación, se proponen preguntas sobre cómo hacer de la equidad una condición del proceso formativo y no solamente un factor cuantitativo de ingreso. Esto supone buscar alternativas para la acción coordinada y continuada desde los niveles educativos que anteceden a la formación profesional universitaria. Lo anterior compromete a los profesionales de la ciencia de la información y la bibliotecología para resignificar su gestión, teniendo en cuenta que su quehacer trasciende lo técnico para asumirse como educadores y pedagogos y generar mecanismos para constituirse en agentes culturales dentro de las instituciones educativas. Se trata de ampliar la naturaleza del papel que como profesionales ejercen en el contexto de la sociedad de la información y centrar su función en tres aspectos: la información, el conocimiento y el aprendizaje.

Lograr estas transformaciones en las formas de actuación de los bibliotecarios en contextos académicos demanda la acción conjunta con profesores y directivas para hacer posible las sinergias a partir de la convergencia de acciones intencionalmente dirigidas hacia el desarrollo de competencias clave para el aprendizaje a lo largo de toda la vida. 


\section{REFERENCIAS}

Almind, T. C. \& Ingwersen, P. (1997), "Informetric analyses on the World Wide Web: Methodological approaches to webmetrics”, en Journal of Documentation, 53, pp. 404-426.

Alvarado, G. (2007), "El concepto de competencia en la perspectiva de la educación superior", presentado en Foro El concepto de competencia: su uso en educación técnica y superior, Universidad Industrial de Santander, 25 de mayo de 2007. Disponible en: http:// groups.google.com/group/alianza-agro/web [Fecha de consulta: 10 de diciembre de 2007].

Álvarez Villar, V. M.; Orozco Hechavarria, O. y Gutiérrez Sánchez, A. (2011), "La formación de competencias investigativas profesionales, una mirada desde las ciencias pedagógicas", en Cuadernos de Educación y Desarrollo, 3 (24), pp. 1-10. Disponible en: http:// www.eumed.net/rev/ced/24/vhs.pdf [Fecha de consulta: 22 de enero de 2013].

Alzate, G. y Peña, L. B. (2010), "La tutoría entre iguales: una modalidad para el desarrollo de la escritura en la educación superior", en Universitas Psychologica, 9 (1), pp. 123-138.

ALA (American Library Association) (1989), Presidential Committee on Information Literacy: Final Report. Association of College and Research Libraries. Disponible en: http://www.ala.org/ala/acrl/ acrlpubs/whirtepaper/prsidential.ttml [Fecha de consulta: 15 de noviembre de 2009].

ACRL (Association of College and Research Libraries) (2000), Information Literacy Competency Standards for Higher Education. Disponible en: http://www.ala.org/ala/acrl/acrlstandards/information literacycompetency.html [Fecha de consulta: 30 de octubre de 2009].

Barbosa-Chacón, J. W.; Barbosa Herrera, J. C.; Marciales Vivas, G.-P. y Castañeda-Peña, H. (2010), "Reconceptualización sobre las competencias informacionales. Una experiencia en la Educación Superior", en Revista de Estudios Sociales, 37, pp. 121-142.

_- Barbosa Herrera, J. C.; Marciales Vivas, G.-P. y Castañeda-Peña, H. (2011), "Dimensión Sociocultural de la Competencia Informacional. Una experiencia de Reconceptualización y Caracterización en el contexto universitario", ponencia presentada en Primera Jornada Nacional de Alfabetización Informacional-ALFIN, Universidad Nacional de Cuyo, 17 y 18 de noviembre de 2011, Mendoza, Argentina.

; Barbosa Herrera, J. C.; Marciales Vivas, G.-P. y Castañeda-Peña, H. (2012), "Observación de la Competencia Informacional en Estudiantes Universitarios”, ponencia presentada en XII Congreso Internacional de Información, Instituto de Información Científica y Tecnológica (IDICT) del Ministerio de Ciencia, Tecnología y Medio Ambiente de la República de Cuba, 14 al 18 de abril de 2012, La Habana, Cuba. 
Bernhard, P. (2002), "La formación en el uso de la información: una ventaja en la enseñanza superior. Situación actual”, en Anales de Documentación, 5, pp. 409-435. Disponible en: http://revistas.um.es/ index.php/analesdoc/article/viewFile/2271/2261 [Fecha de consulta: 12 de enero de 2013].

Batellino, L. J. y Lissera, R. G. (2006), "Nivel de información de los estudiantes de la carrera de Odontología (Universidad Nacional de Córdoba) acerca del conocimiento, metodología e investigaciones científicas", en Educación en Ciencias de la Salud, 3 (1), pp. 27-33. Disponible en: http://www2.udec.cl/ofem/recs/anteriores/vol31 2006/RECS3106.pdf\#page=27 [Fecha de consulta: 12 de enero de 2013].

Broad, J. (2006), "Interpretations of independent learning in further education", en Journal of Further and Higher Education, 30 (2), pp. 119-143. Disponible en: http://santersero.pbworks.com/f/Interpre tations $\% 20$ of $\% 20$ independent $\% 20$ learning.pdf [Fecha de consulta: 15 de enero de 2013].

Cabra-Torres, F. y Marciales Vivas, G. P. (2009), "Mitos, realidades y preguntas de investigación sobre los 'Nativos Digitales': Una revisión”, en Universitas Psychologica, 8 (2), pp. 323-338. Disponible en: http://revistas.javeriana.edu.co/index.php/revPsycho/article/ view/476 [Fecha de consulta: 15 de enero de 2013].

Cardinale, L. (2007), "La lectura y escritura en la universidad. Aportes para la reflexión desde la pedagogía crítica”, en Pilquen, 8 (3), pp. 1-5. Disponible en: http://www.revistapilquen.com.ar/Psicopedagogia/Psico3/3_Cardinale_Lectura.pdf [Fecha de consulta: 14 de enero de 2013].

Castañeda-Peña, H.; González Niño, L.; Marciales Vivas, G. P.; Barbosa-Chacón, J. W. y Barbosa Herrera, J. C. (2010), "Recolectores, Verificadores y Reflexivos: perfiles de la competencia informacional en estudiantes universitarios de primer semestre”, en Revista Interamericana de Bibliotecología, 33 (1), pp. 187-209.

Corona Rodríguez, J. M. (2012), “Acercamientos y propuestas de investigación sobre el consumo y la producción de información en internet. El prosumidor como concepto clave en la construcción social de la tecnología”, en Question, 35 (1), pp. 62-72. Disponible en: http:/www.perio.unlp.edu.ar/ojs/index.php/question/article/ view/1570/1351 [Fecha de consulta: 10 de enero de 2013].

De la Orden, A. (2007), "El Nuevo Horizonte de la Investigación Pedagógica”, en Revista Electrónica de Investigación Educativa, 9 (1), pp. 1-22. Disponible en: http://www.redalyc.org/articulo.oa?id= 15590110 [Fecha de consulta: enero 26 de 2013].

Dochy, F.; Segers, M. \& Dierick, S. (2002), "Nuevas vías de aprendizaje y enseñanza y sus consecuencias: Una nueva era de evaluación”, en Revista Docencia Universitaria, 2 (2), pp. 13-30. Disponible en: http://dialnet.unirioja.es/servlet/articulo?codigo $=258915$ [Fecha de consulta: 26 de enero de 2013]. 
Durán Gisbert, D. y Huerta Córdoba, V. (2008), "Una experiencia de Tutoría entre iguales en la Universidad mexicana de Oaxaca”, en Revista Iberoamericana de Educación, 48 (1), pp. 1-12. Disponible en: http://www.rieoei.org/expe/2693Duran-Maq.pdf [Fecha de consulta: 26 de enero de 2013].

Eshet-Alkalai, Y. (2004), "Digital literacy: A conceptual framework for survival Skills in the Digital Era", en Journal of Educational Multimedia and Hypermedia, 13 (1), pp. 93-106.

Eveland, W. P. \& Dunwoody, S. (2001), "User control and structural isomorphism or disorientation and cognitive load? Learning from the web versus print”, en Communication Research, 28 (1), pp. 48-78.

Fainholc, B. (2004), Lectura Crítica en Internet. Análisis y utilización de los recursos tecnológicos en Educación, México: Homo Sapiens Ediciones.

Ferrer, J. (2003), "La acción tutorial en la universidad”, en Francisco F. Michavila Pitarch y Javier García Delgado (coords.), La tutoría y los nuevos modos de aprendizaje en la universidad, Madrid: Consejería de Educación, Cátedra Unesco de la Universidad Politécnica, pp. 67-84.

Fitzgibbons, M. (2008), Implications of Hypertext Theory for the reading, organizational and retrieval of information. Disponible en: http:// www.webpages.uidaho.edu/ mbolin/fitzgibbons.htm [Fecha de consulta: 22 de enero de 2013].

Garmendia Bonilla, L. (2005), "La alfabetización informacional como estímulo investigativo: Una estrategia en la gestión de la información y el conocimiento", en Biblios, 6 (21), pp. 1-12. Disponible en: http://dialnet.unirioja.es/servlet/articulo?codigo=1281417 [Fecha de consulta: 24 de enero de 2013].

Giurgiu, L. \& Barsan, G. (2008), "The Prosumer-Core and consequence of the web 2.0 era", en Revista de Informatic Social , 9, pp. 53-59. Disponible en: http://www.ris.uvt.ro/wp-content/uploads/ 2009/01/giurgiubirsan.pdf [Fecha de consulta: 10 de enero de 2013].

González Jiménez, O. (2010), "Aprender a aprender, una necesidad de los estudiantes de la Facultad de Agronomía de Montaña de San Andrés, Pinar del Río", en Pedagogía Universitaria, 15 (2). Disponible en: http://cvi.mes.edu.cu/peduniv/index.php/peduniv/article /view/534 [Fecha de consulta: 11 de enero de 2013].

González Moreno, C. X. (2012), "Formación del pensamiento reflexivo en estudiantes universitarios", en Revista Internacional de Investigación en Educación, 4 (9), pp. 595-617. Disponible en: http:// redalyc.uaemex.mx/redalyc/pdf/2810/281022848005.pdf [Fecha de consulta: 14 de enero de 2013].

González Niño, L.; Marciales Vivas, G. P.; Castañeda-Peña, H.; Barbosa-Chacón, J. W. y Barbosa Herrera, J. C. (2013), "Competencia informacional: desarrollo de un instrumento para su observación”, en Lenguaje, 41 (1), pp. 105-131. 
Greimas, A. J. (1989), Del sentido II: ensayos semióticos, Madrid: Gredos. Griffin, M. \& Griffin, B. (1998), "An Investigation of the Effects of Reciprocal Peer Tutoring on Achievement, Self-Efficacy, and Test Anxiety", en Contemporary Educational Psychology, 23 (3), pp. 298311. Disponible en: http://www.sciencedirect.com/science/article/ pii/S0361476X98909717\#pdf [Fecha de consulta: 15 de enero de 2013].

Gualdrón, L y Rey, R. (2002), Construcción de Materiales de Autoaprendizaje, Bucaramanga-Colombia: Ediciones Universidad Industrial de Santander.

Hernández Hernández, P. (2001), Psicología de la educación, México: Trillas.

Hofer, B. K. (2004), "Epistemological Understanding as a Metacognitive Process: Thinking Aloud during Online Searching”, en Educational Psychologist, 39 (1), pp. 43-55.

Marciales Vivas, G. P. (2003), Pensamiento crítico: diferencias en estudiantes universitarios en el tipo de creencias, estrategias e inferencias en la lectura crítica de textos, tesis doctoral, Universidad Complutense de Madrid. Disponible en: http://eprints.ucm.es/tesis/ edu/ucm-t26704.pdf [Fecha de consulta: 14 de enero de 2013].

__; González Niño, L.; Castañeda- Peña, H. y Barbosa Chacón, J. W. (2008), "Competencias informacionales en estudiantes universitarios: una reconceptualización”, en Universitas Psychologica, 7 (3), pp. 613-954.

_ Peña, L. B.; Castañeda-Peña, H.; González Niño, L.; Barbosa-Chacón, J. W. y Barbosa Herrera, J. C. (2010), Competencias Informacionales en estudiantes universitarios: Aportes para su caracterización y desarrollo, Lima, Perú: Pontificia Universidad Católica del Perú. (Serie Temas de Bibliotecología e Información.)

—_ Cabra, F.; Castañeda-Peña, H.; Peña, L. B.; Mancipe, E. y Gualteros, N. (2013), Nativos digitales: transiciones de lo impreso a lo digital, Bogotá: Editorial Pontificia Universidad Javeriana.

Marcos, A. (2011), "Aprender haciendo: Paidea y Phronesis en Aristóteles”, en Educação, 34 (1), pp. 13-24.

Montiel-Overall, P. (2007), "Information Literacy: Toward a Cultural Model", en Canadian Journal of Information and Library Science, 31 (1), pp. 43-68.

Newman, D. P.; Griffin, P. \& Cole, M. (1998), La zona de construcción del conocimiento, 3a. ed., Madrid: Ediciones Morata.

Ochoa Angrino, S. y Aragón Espinosa, L. (2007), "Funcionamiento metacognitivo de estudiantes universitarios durante la escritura de reseñas analíticas", en Universitas Psychologica, 6 (3), pp. 493-506.

Penzo, W.; Fernández, V.; García, I.; Gros, B.; Pagés, T.; Roca, M.; Vallès, A. y Vendrell, P. (2010), Guía para la elaboración de actividades de aprendizaje, Barcelona: Editorial Octaedro. Disponible en: http://www.octaedro.com/ice/pdf/16515.pdf [Fecha de consulta: 15 de enero de 2013]. 
Peña, L. B. (2009), Indagar es preguntarse, Colombia: Pontificia Universidad Javeriana, Facultad de Psicología. Publicación interna.

Prensky, M. (2001), "Digital natives, digital immigrants", en On the Horizont, 9 (5), pp. 1-6.

Raij, K. (2007), Learning by Developing, Finlandia: Laurea Publications. Disponible en: http://markkinointi.laurea.fi/julkaisut/a/a58. pdf [Fecha de consulta: 15 de enero de 2013].

Rodríguez Cobián, A. A. (2009), "El trabajo independiente en los estudiantes de Medicina y la enseñanza de la propedéutica clínica, en el contexto del policlínico universitario", en Ciencia y Sociedad, 35 (1), pp. 133-146. Disponible en: http://www.redalyc.org/articu lo.oa? id=87014565007 [Fecha de consulta: 15 de enero de 2013].

Rosales, Horacio (2008), ¿Qué es competencia? Módulo de actores Alianza Agroindustrial Santander, Colombia: Universidad Industrial de Santander. Disponible en: http://alianzaagroindustrial. blogspot.com/2008/02/mdulo-para-la-formacin-de-los-actores.html [Fecha de consulta: diciembre 15 de 2008].

Serrano Orejuela, E. (2003), El concepto de competencia en la semiótica discursiva. Disponible en: http://www.geocities.com/semiotico [Fecha de consulta: 6 de abril de 2010].

Serrano de Moreno, S. (2008), "El desarrollo de la comprensión crítica en los estudiantes universitarios. Hacia una propuesta didáctica", en Educere, 12 (42), pp. 505-514. Disponible en: http://www.scie lo.org.ve/scielo.php?pid=S1316-49102008000300011\&script=sci_ arttext [Fecha de consulta: 14 de enero de 2013].

Serrano de Moreno, E. y Peña González, J. (2003), "La escritura en el medio escolar: un estudio en las etapas”, en Educere, Investigación Arbitrada, 6 (20), enero-febrero-marzo, pp. 397-408. Disponible en: http://www.saber.ula.ve/bitstream/123456789/19747/1/articu lo6.pdf [Fecha de consulta: 5 de mayo de 2013].

Spivey, N. N. \& King, J. (1989), "Readers and writers composing from sources”, en Reading Research Quarterly, 24 (1), pp. 7-26.

Topping, K. J. (1996), “The Effectiveness of Peer Tutoring in Higher and Further Education: A typology and review of the literature", en Higher Education, 32 (3), pp. 321-345.

Unesco (2006), Information literacy: An international state-of-the art report. Disponible en: http://www.uv.mx/usbi_ver/unesco [Fecha de consulta: 26 de agosto de 2006].

Uribe Tirado, A. (2010), "La alfabetización informacional en la universidad: descripción y categorización según los niveles de integración de ALFIN: caso Universidad de Antioquia”, en Revista Interamericana de Bibliotecología, 33 (1), pp. 31-83. Disponible en: http://www.scielo.org.co/pdf/rib/v33n1/v33n1a02.pdf [Fecha de consulta: 14 de enero de 2013]. 
Valverde Berrocoso, J. y Garrido Arroyo, Ma. del C. (2005), "La función tutorial en entornos virtuales de aprendizaje: comunicación y comunidad”, en RELATEC: Revista Latinoamericana de Tecnología Educativa, 4 (1), pp. 153-167

Van Deursen, A. \& Van Dijk, J. (2008), "Measuring Digital Skills", ponencia presentada en The 58th Annual Conference of the International Communication Association, International Communication Association (ICA), 22-26 de mayo de 2008, Montreal, Canadá.

Vásquez, A. (2008), "La producción de textos académicos a partir de fuentes múltiples y aprendizaje en la universidad: estrategias de la tarea, dificultades de los estudiantes", en Desafíos de la lectura y la escritura en educación superior: caminos posibles, Cali, Colombia: Universidad Autónoma de Occidente, pp. 21-50.

Vonderwell, S. (2003), "An Examination of asynchronous communication experiences and perspectives of students in an online course: a case study", en The Internet and higher education, 6, pp. 77-90. Disponible en: http://www.anitacrawley.net/Articles/Vonderwell(2003).pdf [Fecha de consulta: 10 de enero de 2013].

Wenger, E.; McDermott, R. \& Snyder, W. (2002), Cultivating communities of practice, Boston: Harvard Business School Press. 